\title{
A Comparative Study of Hysteresis Current Controller and PI Controller in Grid-Connected Inverter
}

\author{
Christopher Ngadi Anak Julius ${ }^{1}$, Lailatul Niza Muhammad ${ }^{1}$, Hamdan Daniyal ${ }^{1}$, \\ Norazila Jaalam ${ }^{1}$, Nor Rul Hasma Abdullah ${ }^{1}$ and Suliana Ab Ghani ${ }^{1}$ \\ ${ }^{1}$ Faculty of Electrical \& Electronics Engineering Technology, University of Malaysia Pahang, 26600 Pekan, \\ Malaysia \\ lailatul@ump.edu.my
}

\begin{abstract}
The use of renewable energy sources is highly demand in electricity market nowadays. The incorporation of renewable energy sources with the utility grid has becoming a challenging task in power system as it arises several control issues such as grid stability, power quality control, loads sharing and others. This paper presents current control methods namely Hysteresis controller and Proportional-Integral controller used to interface of single-phase grid connected inverter with nonlinear load. The impact of nonlinear load on grid current is analysed by measuring the performance of total current harmonics distortion $\left(\mathrm{THD}_{\mathrm{i}}\right)$ level in MATLAB ${ }^{\mathrm{TM}}$ Simulink software environment.
\end{abstract}

Key words : $\mathrm{THD}_{\mathrm{i}}$, harmonics, hysteresis current control, power quality, Proportional-Integral, Renewable energy sources

\section{INTRODUCTION}

Nowadays, variety of renewable energy applications which includes solar energy, wind energy, hydro, geothermal, tidal and wave energy had been implemented in distributed generation system. Due to the rapid development of renewable energy technologies, it has steered to the production of low cost renewable power generation. RES are highly demand due to its many advantages such as high sustainability, economic profits and able to provide clean energy which makes it environmental-friendly [1-3].

The integration of renewable energy based on power plant into distributed system leads to the rise of power electronic converters' usage. The power generated by renewable energy sources based distributed generation is transformed by converter into the form of power that is reconcilable with distributed grid. However, the power exchange between DG and the grid raises several control issues. One of the challenging issues is power quality control. The presence of harmonics due to combination between VSI and DC with grid or nonlinear loads causes voltage and current signals to be distorted and injected into the grid by DG inverter [4-8].
Various current control strategies had been proposed by researchers to compensate harmonics content in output waveform of inverter. The most significant current control strategies include PI control, predictive current controller, state feedback controller, ramp time current controller and hysteresis controller [9-12]. The application of PI controller can be seen in single phase inverter connected to grid [13-15].

Inverter and non-linear load generate unwanted harmonics distortion which cause reduction in power quality. Good quality current injected into the grid can also be achieved through modified PI controller by eliminating the steady state error in closed-loop system [16]. Hysteresis controller is another type of current controller that is commonly applied in control system application due to its directness and fast response. One of the disadvantages of hysteresis controller is that it has high switching frequency which leads to undesirable harmonics. A modified hysteresis controller is presented to reduce switching losses in grid-connected inverter system [17-19]. The proposed hysteresis controller is proven to have the ability to minimise switching losses without sacrificing output current waveform.

This paper aims to assess the control performance of three current control techniques, which are hysteresis, PI and combination of hysteresis with PI controller. A single-phase grid connected inverter with nonlinear load act as the testing platform of the project. The results which indicates the behavior of each current control techniques being tested under controlled condition are analysed and compared.

\section{SINGLE-PHASE GRID CONNECTED INVERTER SETUP}

There are three major components needed in single-phase grid connected inverter; the inverter, the grid and the load. By referring to Figure 1, DC voltage supply is used to supply voltage to be fed to the voltage source inverter. VSI converts DC to AC voltage to be delivered into the utility grid. RLC filter helps to filter out switching harmonics of Pulse Width Modulation (PWM). 


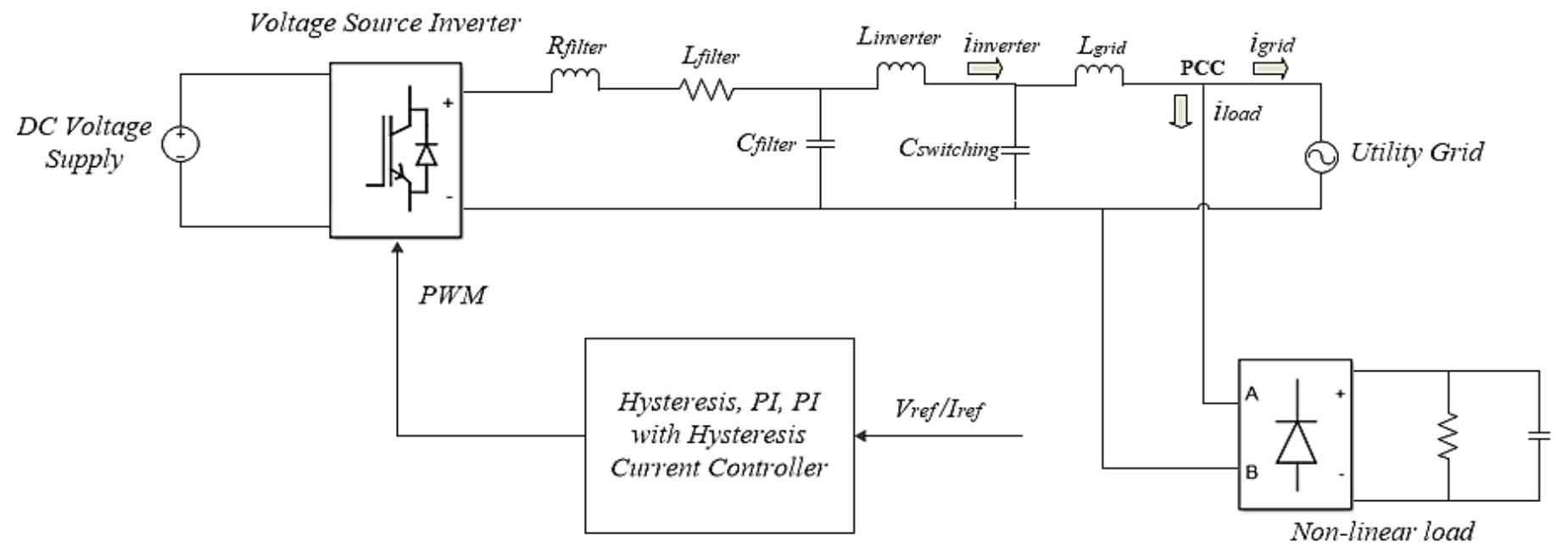

Figure 1: Overall system configuration of single-phase grid connected inverter with nonlinear load.

Switching capacitor, $C_{\text {switching }}$ removes the switching components on point-of-common-coupling (PCC) from entering the grid while inverter inductance allows ripples in source current. Grid inductance, $L_{\text {grid }}$ exists as the grid impedance and non-linear load draws distorted harmonics current into the grid. Hysteresis controller and PI controller compensate the harmonics content in the grid current. Bipolar PWM is generated through the PWM technique to be fed into the inverter.

For synchronization between the inverter and the grid, this project does not require Phase-Locked-Loop (PLL) method. This is because the reference voltage is directly taken from the grid voltage whereas the reference current is taken from the output current of inverter. Through this method, it is more robust and constructive compared to conventional reference signal generation as this method can minimize cost and lessen the number of components such as PLL. Note that the desired voltage waveform must be obtained first in order to control the current waveform.

Table 1 below synopses the parameters used in the system.

Table 1: System parameters of simulation project

\begin{tabular}{|c|c|}
\hline Parameter & Value \\
\hline DC Voltage supply & $250 \mathrm{~V}$ \\
\hline Grid voltage & $110 \mathrm{~V}_{\mathrm{rms}}$ \\
\hline Line frequency & $50 \mathrm{~Hz}$ \\
\hline Switching frequency, $\mathrm{f}_{\mathrm{sw}}$ & $11.1 \mathrm{kHz}$ \\
\hline & $\mathrm{R}_{\mathrm{f}}=0.2 \Omega$ \\
RLC filter & $\mathrm{L}_{\mathrm{f}}=2.5 \mathrm{mH}$ \\
& $\mathrm{C}_{\mathrm{f}}=11 \mathrm{mF}$ \\
\hline Nonlinear load & $\mathrm{R}_{\text {load }}=88 \Omega$ \\
& $\mathrm{C}_{\text {load }}=470 \mu \mathrm{F}$ \\
\hline Inverter inductance, $\mathrm{L}_{\text {inv }}$ & $5 \mathrm{mH}$ \\
\hline Switching capacitor, $\mathrm{C}_{\text {switching }}$ & $15 \mu \mathrm{F}$ \\
\hline Grid impedance, $\mathrm{L}_{\text {grid }}$ & $15 \mathrm{mH}$ \\
\hline
\end{tabular}

\section{CURRENT CONTROL TECHNIQUES}

There are three current control methods being compared in this paper. The main reason of choosing hysteresis controller and PI controller is due to their simplicity and easily understood.

\subsection{Hysteresis Current Control}

Since hysteresis current control is simple and easy to be implemented, it is widely used in grid-connected inverters mode. The operation of this control system works by comparing the measured output current of the single phase inverter with the reference current. As the controller produces switching pulses for the IGBTs, a fixed hysteresis bandwidth which consists of upper limit and lower limit is used to control the error of current within its range. The switches S1 and S4 are at $\mathrm{ON}$ state when the current error reaches the upper limit while $\mathrm{S} 2$ and $\mathrm{S} 3$ are turned $\mathrm{ON}$ if the current error meets the lower limit. Figure 2 and Figure 3 below show the hysteresis controller block diagram and switching pattern of hysteresis current control waveform.

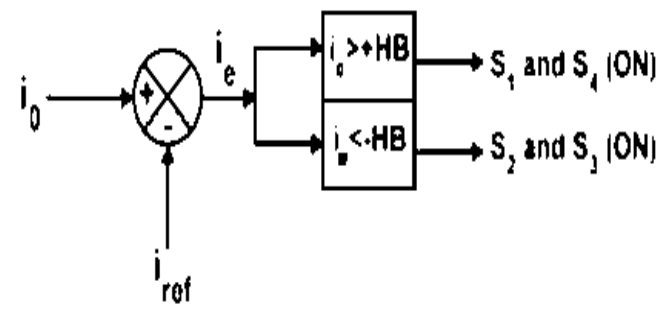

Figure 2: Hysteresis controller block diagram [19]

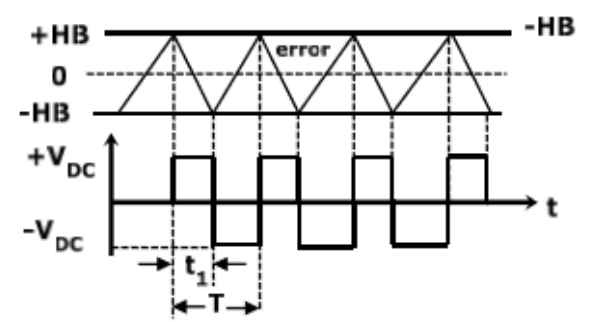

Figure 3: Switching pattern of hysteresis current control [19] 
In order to achieve desired reference current tracking, the hysteresis bandwidth, $h$ can be determined by this equation:

$$
\mathrm{h}=\frac{\left(\mathrm{Vdc}^{2}-\mathrm{Vgrid}^{2}\right)}{4 \mathrm{VdcL}}
$$

The current error is controlled by calculating the switching frequency of the inverter connected to grid. The switching cycle is expressed by $0 \rightarrow t_{1}$ period, where:

$$
t_{1}=T_{O N}=\frac{2 L_{f} H B}{V_{D C}-V_{\text {grid }}}
$$

For $t_{1} \rightarrow T$ period, the equation can be computed as:

$$
T-t_{1}=T_{O F F}=\frac{2 L_{f} H B}{V_{D C}+V_{\text {grid }}}
$$

The simulation modelling of hysteresis controller is shown in Figure 4 below. The generation of $\mathrm{I}_{\text {ref }}$ is taken from the output current from inverter whereas the measured current is referred to output current from grid, $I_{\text {grid. }}$ The error between both reference and measured current are controlled in a region containing upper and lower limit called hysteresis band.

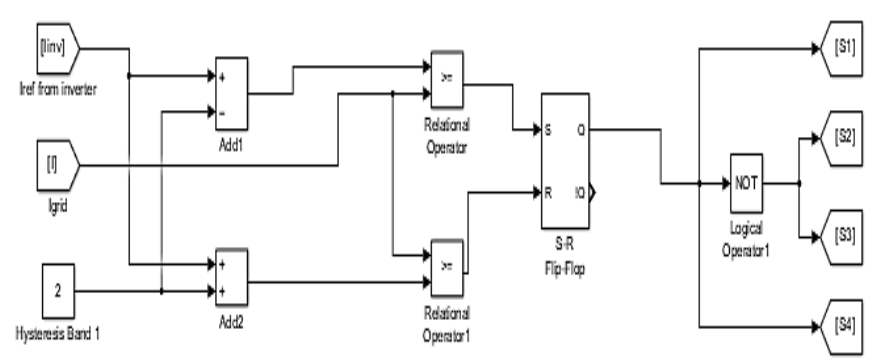

Figure 4: Hysteresis controller simulation block

\subsection{Proportional-Integral Controller}

Proportional Integral (PI) controller is the most ordinary and widely used controller due to its simplicity and better stability in control system. $\mathrm{P}$ controller adds integral component in transfer function to eliminate steady state error.

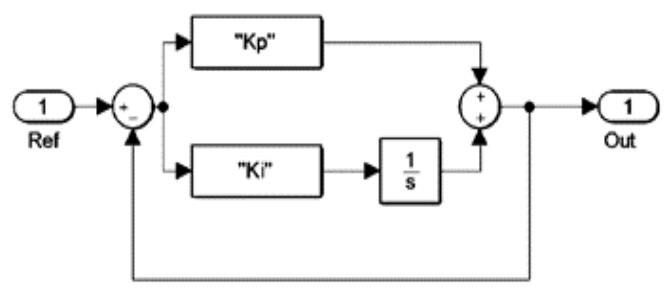

Figure 5: Proportional-Integral controller block diagram

There are several methods to design PI controller such as Ziegler-Nichols method, pole-placement method, frequency response and others. However, in this system, the design of PI controller is taken from [20]. The transfer function of PI controller can be expressed as:

$$
\mathrm{PI}(\mathrm{s})=\mathrm{K}_{\mathrm{p}}+\frac{\mathrm{K}_{\mathrm{s}}}{\mathrm{s}}
$$

where $K_{p}$ refers to Proportional $(P)$ term and $\frac{K_{s}}{s}$ is the Integral (I) term. The tuning method being applied is trial and error. Since there are two loops of controller, $\mathrm{K}_{\mathrm{p}}$ value in outer voltage control is first increased until it reaches the desired output value, followed by $\mathrm{K}_{\mathrm{i}}$ value until the system achieves steady state. After the $\mathrm{K}_{\mathrm{p}}$ and $\mathrm{K}_{\mathrm{i}}$ values in outer voltage control has been fixed, the $\mathrm{K}_{\mathrm{p}}$ and $\mathrm{K}_{\mathrm{i}}$ values in inner current control are adjusted until the system is stable. The design structure of PI controller used in this system is shown in Figure 6 below.

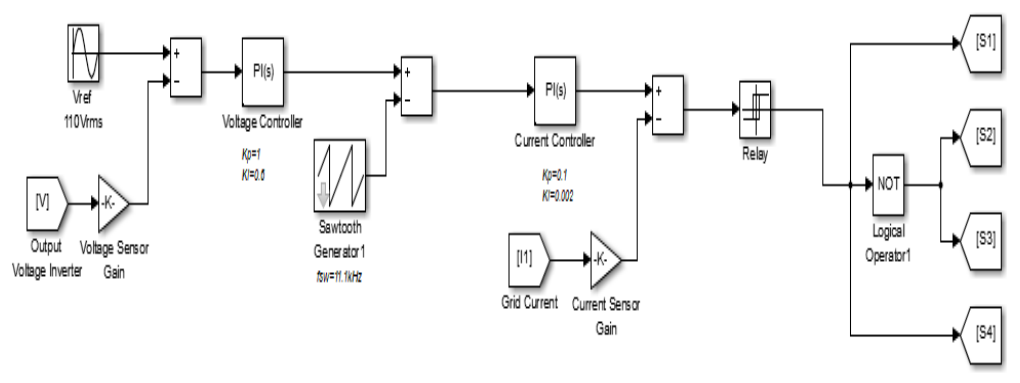

Figure 6: Proportional-Integral controller simulation block

\subsection{PI with Hysteresis Current Controller}

Figure 7 presents the generation of reference current, $I_{\text {ref }}$ in PI with hysteresis current controller. First, the reference voltage, $\mathrm{V}_{\text {ref }}$ which is referred to grid voltage is compared with output voltage of inverter, $\mathrm{V}_{\text {inv }}$. The error generated from both signals are reduced by PI controller. $\mathrm{I}_{\text {ref }}$ coming out from the PI controller will be compared with the output grid current, $\mathrm{I}_{\text {grid }}$ to be regulated by hysteresis band to produce switching pulses for gate signals.

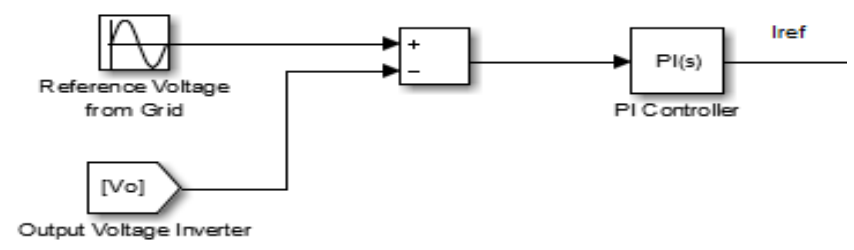

Figure 7: Iref generation for PI with hysteresis current controller

The expression for PI controller is equal to:

$$
\mathrm{PI}(\mathrm{s})=\mathrm{K}_{\mathrm{p}}+\frac{\mathrm{K}_{\mathrm{s}}}{\mathrm{s}}
$$

Where $K_{p}$ tends to reduce the error between reference current and measured current while $\frac{\mathrm{K}_{\mathrm{S}}}{\mathrm{s}}$ controls the oscillation of the system. The reference current that came out from the PI controller will enter the hysteresis band in order to regulate its error within certain range. The output current from inverter can be given as:

$$
\mathrm{I}_{\mathrm{o}}=\mathrm{i}_{\mathrm{ref}}+\mathrm{e}
$$

Thus, deviation of error can be written as:

$$
\frac{d e}{d t}=\frac{V d c-V g r i d}{L f}
$$

As IGBT switch 1 and 4 is ON, the error of current changes 
from negative $\mathrm{HB}$ to positive $\mathrm{HB}$. The $\mathrm{ON}$ time interval can be calculated as:

$$
\mathrm{T}_{\mathrm{ON}}=\frac{2 L f H B}{V d c-\text { Vgrid }}
$$

When IGBT switch 2 and 3 is ON, similar method can be applied where the equation is given as:

$$
\mathrm{T}_{\mathrm{ON}}=\frac{2 L f H B}{V d c+\text { Vgrid }}
$$

By combining equation (8) and (9), the switching frequency of the system is:

$$
\mathrm{f}_{\mathrm{s}}=\frac{\left(V d c^{2}-V g r i d^{2}\right)}{4 V d c L f H B}
$$

The overall Simulink block design of PI with hysteresis current controller is demonstrated in Figure 8 below.

\section{PERFORMANCE MEASURES}

In this paper, the evaluations of the current control techniques are analysed through First Fourier Transform (FFT) analysis. Through the analysis, it gives insight about the dynamic performance of the current control techniques. Harmonics content in a current waveform is measured through Total Current Harmonics Distortion $\left(T H D_{i}\right)$.

It can be expressed as the summation of all harmonics component of the current waveform against the fundamental frequency of current as shown in equation (11).

This means that the output of a system receives the same fundamental frequency as the input when a sinusoidal input is applied with nonlinear system. Higher percentage of $T H D_{i}$ indicates that more distortions are present in the waveform.

$$
T H D_{i}=\frac{1}{I_{\text {resultant }, 1}} \sqrt{\sum_{n=2}^{\infty} I_{\text {resultant }, n}^{2}} \cdot 100 \%
$$

Every project should comply with a benchmark set by certain standards. In this project, the standard for current harmonics distortion used is IEEE 519-2014 [21] which stated that $T H D_{i}$ must below than $5 \%$.

\section{RESULTS \& DISCUSSIONS}

Table 2: $\mathrm{THD}_{\mathrm{i}}$ values of Igrid without and with current controllers

\begin{tabular}{|c|c|c|c|c|}
\hline & $\begin{array}{c}\text { Without } \\
\text { current } \\
\text { controller }\end{array}$ & Hysteresis & PI & PI with \\
controller & controller & $\begin{array}{c}\text { hysteresis } \\
\text { controller }\end{array}$ \\
\hline $\begin{array}{c}\text { THD }_{\mathbf{i}} \\
(\%)\end{array}$ & 48.48 & 5.47 & 5.68 & 5.53 \\
\hline
\end{tabular}

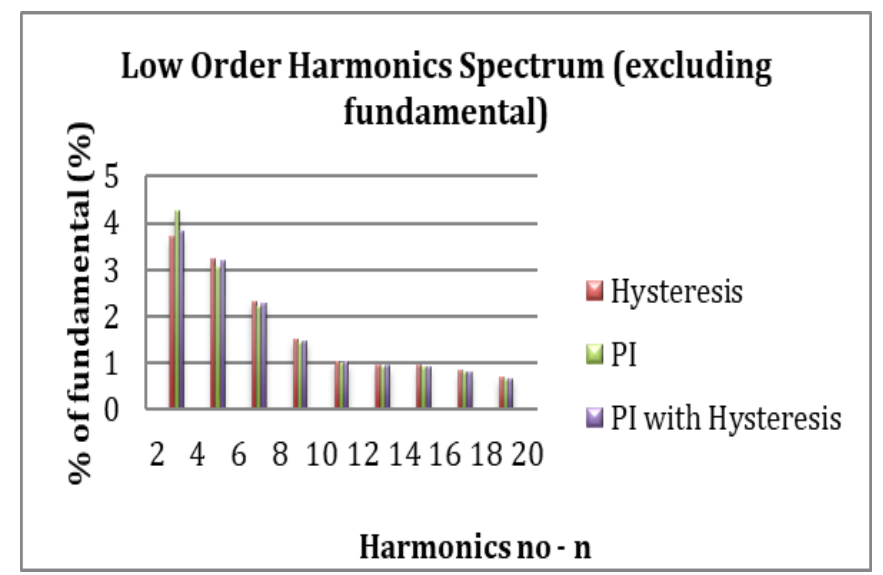

Figure 9: Harmonics spectrum of $I_{\text {grid }}$ given by all three current controllers

From the $\mathrm{THD}_{\mathrm{i}}$ values obtained which are presented in Table 2, PI controller is observed to deliver the highest distortion due to its slow response, resulting in non-zero steady state error. Hysteresis controller shows better total harmonic distortion than PI controller due to its fast response current loop but have low order harmonics and variation in switching frequency. The combination of PI with hysteresis current controller makes the system more robust. Figure 9 shows the lower order harmonics spectrum of $I_{\text {grid }}$ of all three current control methods. The fundamental component is excluded in order to highlight the harmonic content. Hysteresis current controller displayed the highest harmonic content from $5^{\text {th }}$ order to $19^{\text {th }}$ order of harmonics. This is because hysteresis current controller allows the current to flow freely within its hysteresis band, resulting in lower order harmonics.

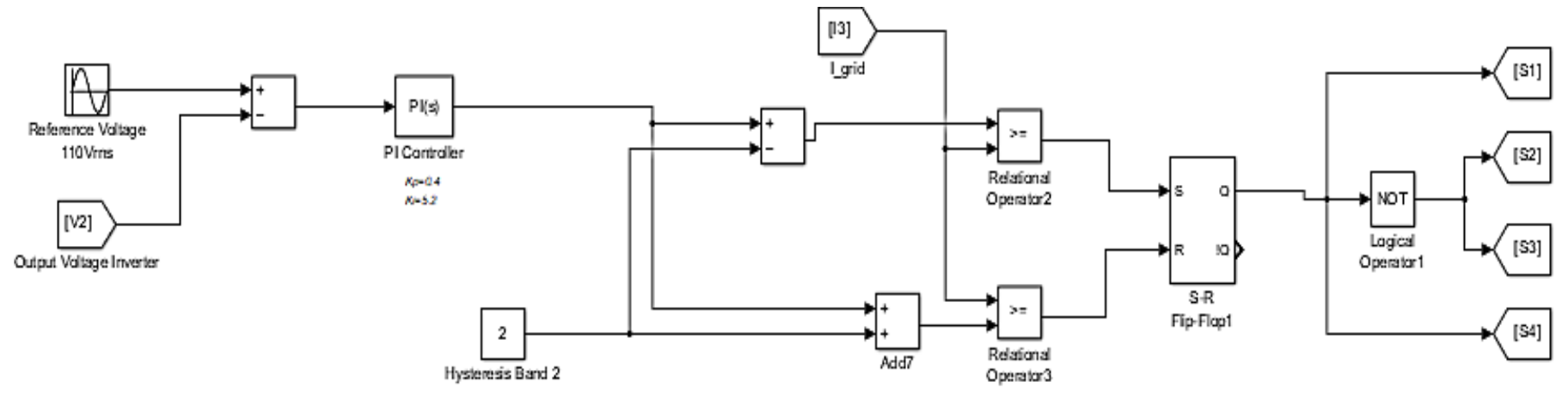

Figure 8: PI with hysteresis current controller simulation block 
Table 3: Comparison of $\mathrm{V}_{\text {inv, }}$ Igrid, and $\mathrm{THD}_{\mathrm{i}}$ of Igrid

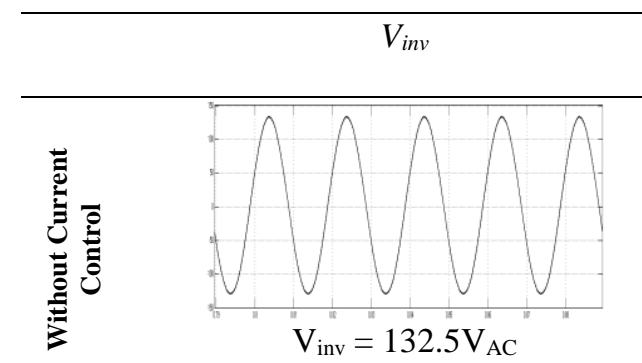

(a)

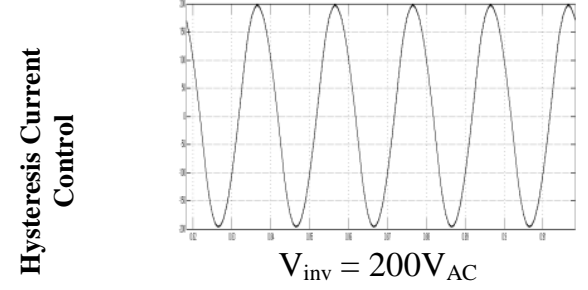

(d)

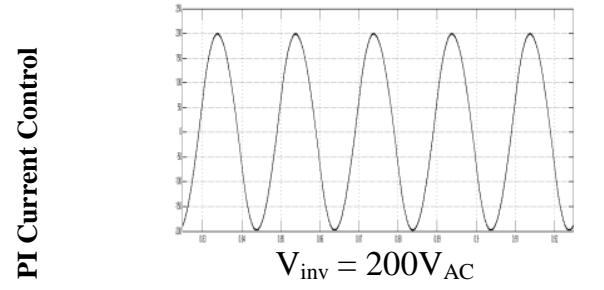

(g)

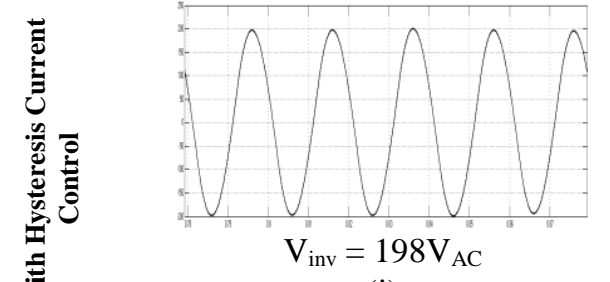

(j)
$I_{\text {grid }}$

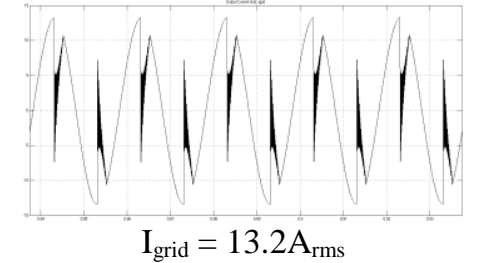

(b)

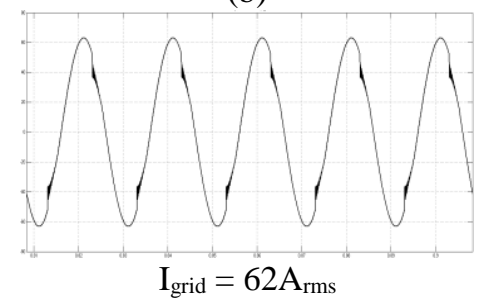

(e)

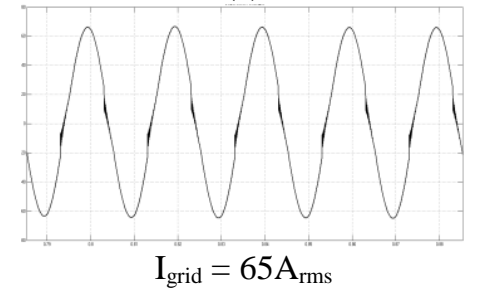

(h)

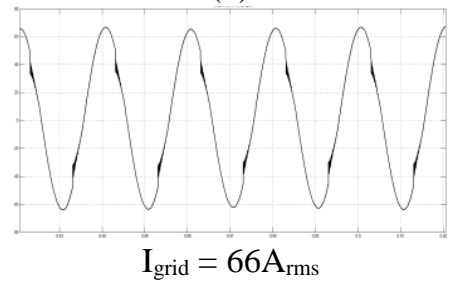

(k)
$T H D_{i}$ of $I_{\text {grid }}$

\section{(1)}

Apart from that, variation in switching frequency of hysteresis current controller also contributes to this factor. The higher order harmonics is absent in the harmonic spectrum. This is because there are inductance being used in the circuit of project. Inductance is represented as $\mathrm{R}+\mathrm{j} w \mathrm{~L}$, where $w$ is equal to $2 \pi \mathrm{f}$. The inductance is directly proportional to the frequency. When impedance is high, the order of harmonics also increases, resulting in lesser magnitude as compared to lower order harmonics. This is why filters are used to block the higher order harmonics.

Table 3 summarise the overall performance of all three controllers in terms of $\mathrm{V}_{\text {inv }}, \mathrm{I}_{\text {grid }}$ and $\mathrm{THD}_{\mathrm{i}}$ level. The output voltage of inverter, $\mathrm{V}_{\text {inv }}$ increases from $132.5 \mathrm{~V}$ to the range of $198-200 \mathrm{~V}$ after current control is added. The same goes for output grid current, $\mathrm{I}_{\text {grid }}$ that shows rise in value from $13 \mathrm{~A}$ to the range of $65-66 \mathrm{~A}_{\mathrm{rms}}$ with current control in the system.

Before current control strategies are added to the system, the output grid current, Igrid is highly distorted which reduces the power quality of the system. The non-sinusoidal distortion problem however managed to be overcome through the application of PI controller, hysteresis current controller and PI with hysteresis current controller. Hysteresis current controller exhibits the best result of $\mathrm{THD}_{\mathrm{i}}$ of $5.47 \%$, followed by $5.53 \%$ of PI with hysteresis current controller and $5.68 \%$ of PI controller. Although hysteresis current controller have variation in switching frequency, it has fast current response which displays a good dynamic performance. PI controller unable to generate the lowest $\mathrm{THD}_{\mathrm{i}}$ level of $\mathrm{I}_{\text {grid }}$ because it has several drawbacks such as slow dynamic response and non-zero steady state error. When both controllers are combined together, the system is considered to be more stable and reliable enough to mitigate any sorts of harmonic content in signals.

\section{CONCLUSION}

In this paper, the simulation study of single phase grid-connected inverter with PI, hysteresis and combination of PI with hysteresis controller has been presented. From the simulation results, it is proven that hysteresis controller exhibits the best and fast current control response, followed by combination PI with hysteresis controller which makes the system sturdier and PI controller as the third best due to its inability to inherit zero steady state error. All current 
controllers proposed in this paper managed to improve the waveform quality without affecting the output voltage of inverter by eliminating the impact of nonlinear load on the grid current.

\section{ACKNOWLEDGEMENTS}

This work has been supported by University of Malaysia Pahang (Grant number: RDU1703221) and the Ministry of Higher Education of Malaysia.

\section{REFERENCES}

1. R. Arun, K. S. Mohammed Gohar Latheef, and G. Anandhakumar, "Grid interconnection of renewableenergy sources at the distribution level with power-quality improvement features," Int. J. Appl. Eng. Res., 2015.

2. H. R. Pota, M. J. Hossain, M. A. Mahmud, and R. Gadh, "Control for microgrids with inverter connected renewable energy resources," in IEEE Power and Energy Society General Meeting, 2014. https://doi.org/10.1109/PESGM.2014.6938911

3. K. T. Tan, P. L. So, Y. C. Chu, and M. Z. Q. Chen, "Coordinated Control and Energy Management of Distributed Generation Inverters in a Microgrid," IEEE Trans. Power Deliv., 2013.

4. A. Menti, T. Zacharias, and J. Milias-Argitis, "Harmonic distortion assessment for a single-phase grid-connected photovoltaic system," Renew. Energy, 2011.

https://doi.org/10.1016/j.renene.2010.07.001

5. X. Liang and C. Andalib-Bin-Karim, "Harmonics and Mitigation Techniques Through Advanced Control in Grid-Connected Renewable Energy Sources: A Review," IEEE Trans. Ind. Appl., 2018. https://doi.org/10.1109/IAS.2017.8101861

6. Y. Yang, K. Zhou, and F. Blaabjerg, "Current Harmonics from Single-Phase Grid-Connected Inverters-Examination and Suppression," IEEE J. Emerg. Sel. Top. Power Electron, 2016. https://doi.org/10.1109/JESTPE.2015.2504845

7. Z. Yao and L. Xiao, "Control of single-phase grid-connected inverters with nonlinear loads," IEEE Trans. Ind. Electron., 2013.

8. Rohit Kumar et al., "A Review of Custom Power Devices for Power Quality Improvement of Distribution Network with Arc Furnace," Int. J. Adv. Trends Comput. Sci. Eng., vol. 8, no. 2, pp. 225-230, 2019.

https://doi.org/10.30534/ijatcse/2019/19822019

9. M. Parvez, M. F. M. Elias, N. A. Rahim, and N. Osman, "Current control techniques for three-phase grid interconnection of renewable power generation systems: A review," Solar Energy. 2016.

10. H. Daniyal, E. Lam, L. J. Borle, and H. H. C. Iu, "Hysteresis, PI and Ramptime Current Control Techniques for APF: An experimental comparison," in Proceedings of the 2011 6th IEEE Conference on
Industrial Electronics and Applications, ICIEA 2011, 2011.

11. A. Chatterjee and K. B. Mohanty, "Current control strategies for single phase grid integrated inverters for photovoltaic applications-a review," Renewable and Sustainable Energy Reviews. 2018.

12. K. Zeb et al., "A comprehensive review on inverter topologies and control strategies for grid connected photovoltaic system," Renewable and Sustainable Energy Reviews. 2018.

13. A. Nachiappan, K. Sundararajan, and V. Malarselvam, "Current controlled voltage source inverter using hysteresis controller and PI controller," in 2012 International Conference on Power, Signals, Controls and Computation, EPSCICON 2012, 2012.

14. T. C. A. Ajot, S. Salimin, and R. Aziz, “Application of PI Current Controller in Single Phase Inverter System Connected to Non Linear Load," in IOP Conference Series: Materials Science and Engineering, 2017.

15. V. K. Chaithanya, A. Pandian, R. B. R. Prakash, and C. R. Reddy, "Analysis of Closed Loop control of Cascaded Three Phase Grid Tied Inverter using Fuzzy Logic Controller," Int. J. Adv. Trends Comput. Sci. Eng., vol. 8, no. 4, pp. 1123-1127, 2019. https://doi.org/10.30534/ijatcse/2019/1984

16. A. I. Maswood and M. A. Rahman, "Performance parameters of a pulse-width modulation voltage source inverter with proportional-integral controller under non-ideal conditions," Electr. Power Syst. Res., 1996.

17. A. I. Putri, A. Rizqiawan, F. Rozzi, N. Zakkia, Y. Haroen, and P. A. Dahono, "A hysteresis current controller for grid-connected inverter with reduced losses," in 2016 2nd International Conference of Industrial, Mechanical, Electrical, and Chemical Engineering, ICIMECE 2016, 2017.

18. B.-J. Kang and C. M. Liaw, "Robust hysteresis current-controlled PWM scheme with fixed switching frequency," IEE Proc. Electr. Power Appl., 2001.

19. S. Jena, B. Mohapatra, C. K. Panigrahi, and S. K. Mohanty, "Power quality improvement of 1- $\varphi$ grid integrated pulse width modulated voltage source inverter using hysteresis Current Controller with offset band," in ICACCS 2016 - 3rd International Conference on Advanced Computing and Communication Systems: Bringing to the Table, Futuristic Technologies from Arround the Globe, 2016. https://doi.org/10.1109/ICACCS.2016.7586349

20. S. M. Cherati, N. A. Azli, S. M. Ayob, and A. Mortezaei, "Design of a current mode PI controller for a single-phase PWM inverter," in 2011 IEEE Applied Power Electronics Colloquium, IAPEC 2011, 2011. https://doi.org/10.1109/IAPEC.2011.5779864

21. I. P. and E. Society, "IEEE Recommended Practice and Requirements for Harmonic Control in Electric Power Systems IEEE Power and Energy Society," ANSI/IEEE Std. 519, 2014. 